\title{
Are Greenhouse Gas Signals of Northern Hemisphere winter extra-tropical cyclone activity dependent on the identification and tracking algorithm?
}

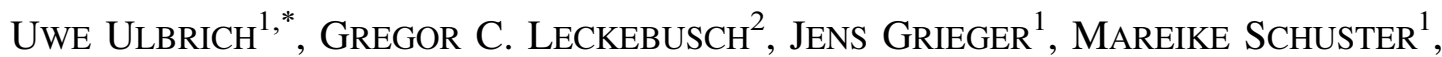

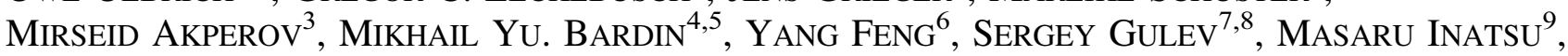
KeVIN KeAY ${ }^{10,11}$, SARAH F. KEW ${ }^{12}$, MARGARIDA L. R. LIBERATO ${ }^{13,14}$, PIERO LiONello ${ }^{15,16}$, IgOR I. MOKhOV ${ }^{3}$, Urs Neu ${ }^{17}$, JoAquim G. Pinto ${ }^{18}$, Christoph C. RaIBle ${ }^{19}$, Marco Reale ${ }^{15,20}$,

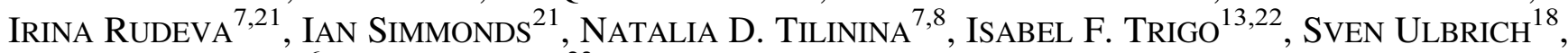
XiAOLAN L. WANG ${ }^{6}$, HEINI WERNLI ${ }^{23}$ and THE IMILAST TEAM

${ }^{1}$ Institute of Meteorology, Freie Universität Berlin, Berlin, Germany

${ }^{2}$ School of Geography, Earth and Environmental Sciences, University of Birmingham, Birmingham, U.K.

${ }^{3}$ A. M. Obukhov Institute of Atmospheric Physics, Russian Academy of Sciences, Moscow, Russia

${ }^{4}$ Institute of Geography, Russian Academy of Sciences, Moscow, Russia

${ }^{5}$ Institute of Global Climate and Ecology, Roshydromet and Russian Academy of Sciences, Moscow, Russia

${ }^{6}$ Climate Research Division, Environment Canada, Toronto, Ontario, Canada

${ }^{7}$ P.P.Shirshov Institute of Oceanology, Russian Academy of Sciences, Moscow, Russia

${ }^{8}$ Moscow State University, Moscow, Russia

${ }^{9}$ Graduate School of Science, Hokkaido University, Sapporo, Hokkaido, Japan

${ }^{10}$ School of Earth Sciences, University of Melbourne, Melbourne, Victoria, Australia

${ }^{11}$ Bureau of Meteorology, Melbourne, Australia

${ }^{12}$ Earth System Science Group, Wageningen University, Wageningen, The Netherlands

${ }^{13}$ Instituto Dom Luiz (IDL), University of Lisbon, Lisbon, Portugal

${ }^{14}$ School of Sciences and Technology, University of Trás-os-Montes e Alto Douro (UTAD), Vila Real, Portugal

${ }^{15}$ DI.S.TE.B.A., University of Salento, Lecce, Italy

${ }^{16} \mathrm{CMCC}$, EuroMediterranea Center on Climate Change, Lecce, Italy

${ }^{17}$ ProClim-, Swiss Academy of Sciences, Bern, Switzerland

${ }^{18}$ Institute of Geophysics and Meteorology, University of Cologne, Cologne, Germany

${ }^{19}$ Climate and Environmental Physics and Oeschger Center for Climate Change Research, University of Bern, Bern, Switzerland

${ }^{20}$ University of Trieste, Department of Mathematics and Informatics, Trieste, Italy

${ }^{21}$ School of Earth Sciences, University of Melbourne, Melbourne, Victoria, Australia

${ }^{22}$ Institute of Meteorology I.P., Lisbon, Portugal

${ }^{23}$ Institute for Atmospheric and Climate Science, ETH Zürich, Zürich, Switzerland

(Manuscript received July 30, 2012; in revised form November 23, 2012; accepted December 3, 2012)

\begin{abstract}
For Northern Hemisphere extra-tropical cyclone activity, the dependency of a potential anthropogenic climate change signal on the identification method applied is analysed. This study investigates the impact of the used algorithm on the changing signal, not the robustness of the climate change signal itself. Using one single transient AOGCM simulation as standard input for eleven state-of-the-art identification methods, the patterns of model simulated present day climatologies are found to be close to those computed from re-analysis, independent of the method applied. Although differences in the total number of cyclones identified exist, the climate change signals (IPCC SRES A1B) in the model run considered are largely similar between methods for all cyclones. Taking into account all tracks, decreasing numbers are found in the Mediterranean, the Arctic in the Barents and Greenland Seas, the mid-latitude Pacific and North America. Changing patterns are even more similar, if only the most severe systems are considered: the methods reveal a coherent statistically significant increase in frequency over the eastern North Atlantic and North Pacific. We found that the differences between the methods considered are largely due to the different role of weaker systems in the specific methods.
\end{abstract}

Keywords: Climate Change, Extra-tropical cyclones, ECHAM5, IMILAST.

\footnotetext{
${ }^{*}$ Corresponding author: Uwe Ulbrich, Institute of Meteorology, Freie Universität Berlin, Carl-Heinrich-Becker-Weg 6-10, 12165 Berlin, Germany, e-mail: ulbrich@met.fu-berlin.de
} 


\section{Introduction}

Mid-latitude cyclones are a feature of key interest with respect to anthropogenic climate change, as their occurrence (or absence) causes a range of weather events affecting human life. Climate models can provide projections of changes in the intensity and frequency of relevant weather situations, such as extreme wind or rainfall, extreme drought or heat waves. The reliability of model results in terms of climate change is usually addressed by comparing the simulated present day climatologies with observational data (up to a weighting of results according to agreement with observational data, e.g., LECKEBUSCH et al., 2008). There are potential shortcomings to this approach: One is that the model may produce a realistic climatology for the wrong reasons (e.g., due to a cancellation of errors), while another is that the climatology may be not realistic (in terms of a bias), but the results are still useful after a simple bias correction. Because of this, it is desirable to evaluate a broad range of aspects of model performances and seek a better understanding of "what the model does" beyond the simple comparison of the impact parameter statistics. In the mid-latitudes, consideration of cyclone behaviour and its changes is an important step into this direction.

The quantification of trends or changes in cyclone occurrence, as well as the detection of extremes, is not independent of the specific methodologies used for cyclone identification and tracking applied to observational data (e.g., TRIGO, 2006) and models. Even the sign of trends within a data set may sometimes depend on the methodology applied to identify and track cyclones (RAIBLE et al., 2008; ULBRICH et al., 2009). As described in detail in NEU et al. (2012), different methodologies are based on a range of parameters for a quantitative description of cyclones, different assumptions on what types of features should be considered a cyclone, and which out of several choices should be considered the track of such a feature between different time steps. The IMILAST initiative (Intercomparison of mid latitude storm diagnostics; http://www.proclim.ch/imilast/index.html), aiming at a better understanding of these differences (NEU et al., 2012), is an international collaboration of a number of groups developing and applying procedures for cyclone identification, tracking and quantification. While its initial goal was to gain this understanding from observed cyclones as represented in reanalysis, the logical next step is a comparison of cyclone change signals in simulations performed under anthropogenic climate change conditions.

The present paper focuses on the cyclone analysis conducted on the output of one particular model simulation which has been used in several previous investigations, and which proved to be close to the ensemble mean in a study on synoptic activity changes in CMIP3 (ULBRICH et al., 2008). The different representations of climate change signals by various AOGCMs are not discussed. The goal here is to identify both similarities and differences in the cyclone climatologies produced by 11 state-of-the-art cyclone tracking schemes (see Table 1) from the results of the same AOGCM run. The investigation is conducted for modelled conditions for both current climate and for the last four decades of the 21 st century in response to the A1B emission scenario.

\section{Data}

We use here one of the three model simulations (run 1) of the ECHAM5/OM1 model (ROECKNER et al., 2003) driven with observed greenhouse gas concentrations until the year 2000, and driven with the SRES A1B scenario forcings until the year 2100. The resolution of the atmospheric part of the coupled model is T63 and 31 vertical levels up to $10 \mathrm{hPa}$. This model has been used in several studies on both general cyclone characteristics and extreme cyclones using different tracking algorithms (e.g. BengtSSON et al., 2006; PINTO et al., 2007; LÖPTIEN et al., 2008; DELlA-MARTA and PINTO, 2009; SIENZ et al., 2010; SCHNEIDEREIT et al., 2010).

ULBRICH et al. (2008) confirmed that the mean of three ECHAM5/OM1 model runs is very close to a 23 member multi-model ensemble signal in the Northern Hemisphere (NH) 'storm track', as defined by the maximum of the standard deviation of synoptic time scale

Table 1: Contributing IMILAST teams and their algorithms - enumeration is as that used in NEU et al. 2012.

\begin{tabular}{llc}
\hline & \multicolumn{1}{c}{ Methodology } & Intensity parameter \\
\hline M02 & MURRAY and SiMMONDS 1991, PINTO et al. 2005 & MSLP min. \\
M08 & TRIGO 2006 & MSLP min. \\
M09 & SERREZE 1995, WANG et al. 2006, WANG et al. 2012 & MSLP min. \\
M10 & MURRAY and SiMMONDS 1991, SiMMONDS et al. 2008 & MSLP min. \\
M12 & ZOLINA and GULEV 2002, RUDEVA and GULEV 2007 & MSLP min. \\
M14 & KEW et al. 2010 & Z850 min. \\
M15 & BLENDER et al. 1997, RAIBLE et al. 2008 & Z1000 min. \\
M16 & LIONELLO et al. 2002 & MSLP min. \\
M20 & WERNLI and SCHWIERZ 2006 & MSLP min. \\
M21 & INATSU 2009 & Z850 Vort. \\
M22 & BARDIN and POLONSKY 2005, AKPEROV et al. 2007 & MSLP min. \\
\hline
\end{tabular}


(a)

$$
\text { all cyclones }
$$
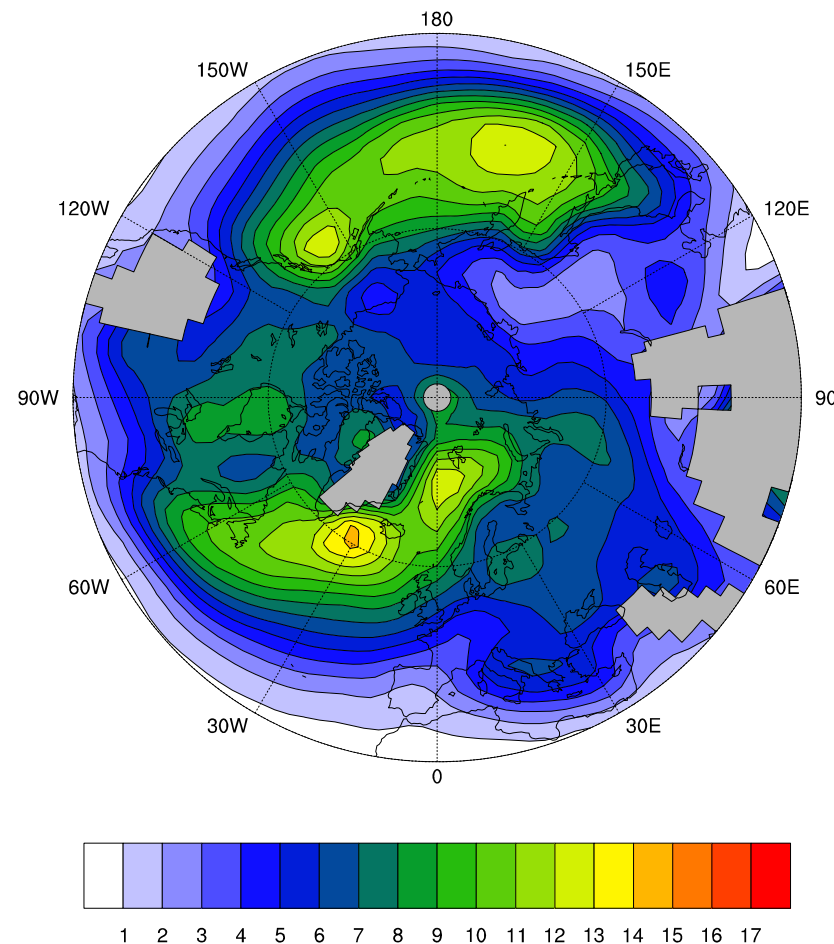

(b)
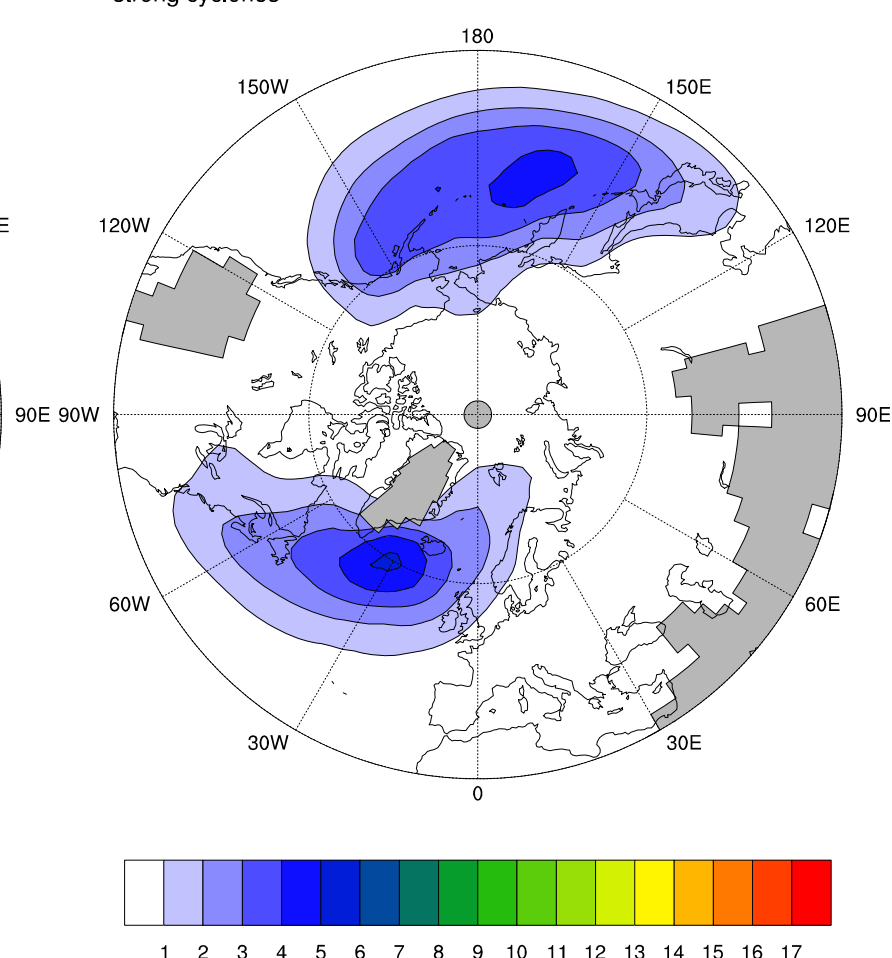

Figure 1: Method mean of winter (DJF) track density [tracks/winter lat ${ }^{-2}$ ] for a) all cyclones and b) strong cyclones for $20 \mathrm{C}$. Areas with orography higher than $1500 \mathrm{~m}$ are masked out with grey shading.

variations of sea level pressure. PINTO et al. (2007) pointed at the fact that for the run used here the identified climate change signal is somewhat stronger than in the other two runs.

While the majority of the analysed 11 cyclone identification and tracking schemes are based on the MSLP (minimum or minimum of the gradient) as identifying variable, one method uses the vorticity at $850 \mathrm{hPa}$ (INATSU, 2009) and another method adapted from KEW et al. (2010) uses the geopotential height at $850 \mathrm{hPa}$. Three methods based on the MSLP additionally take the vorticity into account (PINTO et al., 2005; SIMMONDS et al., 2008; WANG et al., 2012). Detailed information on the characteristics of all the algorithms within IMILAST can be found in NEU et al. (2012).

\section{Results}

Eleven of the methodologies contributing to the IMILAST initiative (references in Table 1) have evaluated the model climatology of cyclones in the $\mathrm{NH}$. The method-mean of winter climatologies from the $20 \mathrm{C}$ period (1961-2000) is shown in Fig. 1a. The figure represents the density of cyclone tracks per winter (DJF) and ${ }^{\circ} \mathrm{lat}^{2}$ on a common $2.5 \times 2.5^{\circ}$ grid, in the sense that all grid boxes crossed by each track are used for the statistics (MURRAY and SIMMONDS, 1991b; PINTO et al., 2005). The spatial distribution of cyclone tracks is dom- inated by maxima over the Atlantic and the Pacific Oceans, over the area commonly denominated as the main North Atlantic and North Pacific storm tracks (e.g. HOSKINS and VALDES, 1990). The differences between the methodologies appear to be rather small, except for method M02 which produces considerably (about 50\%) greater track densities than the other methods (supplemental material ${ }^{1}$ ). With respect to differences in spatial distribution, the methodologies have been compared to the ERA-Interim (DEE et al., 2011) climatologies as discussed in NEU et al. (2012) using a pattern correlation (a latitude weighting was imposed to account for the convergence of the meridians). As expected from previous exercises evaluating the ECHAM5/OM1 20C period against re-analysis data (e.g. BENGTSSON et al., 2006; PINTO et al., 2007; LÖPTIEN et al., 2008), the correlations (Fig. 2) are all rather high. There is a dependence on the methodology, however: methods M09, M12, M20, M21 and M22 produce a correlation lower than 0.9 , while the agreement using the other methods is better than $r=0.95$. The reasons for the differences are not clear, except for M09 where there seems to be an inconsistency close to the North Pole using the model data, which did not occur in the reanalysis, possibly related to the interpolation of data on the model grid to the $50-\mathrm{km}$ EASE

${ }^{1}$ Supplemental information related to this paper is available on the journals website at www.schweizerbart.de/journals/metz. 


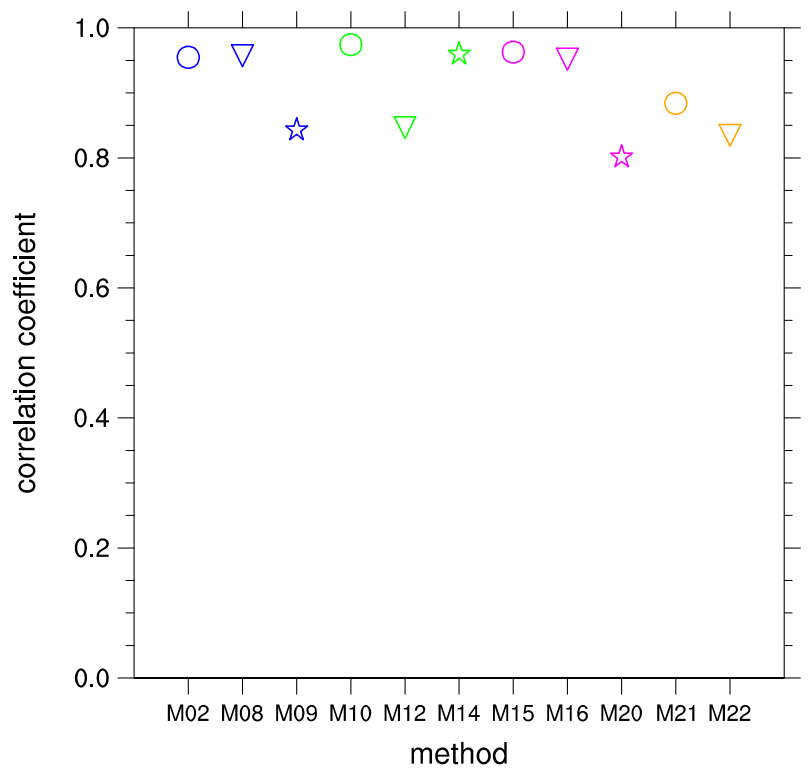

Figure 2: $20 \mathrm{C}$ pattern correlation for the $\mathrm{NH}\left(20^{\circ} \mathrm{N}-90^{\circ} \mathrm{N}\right)$ per method with ERA-Interim pattern per method. Areas with orography higher than $1500 \mathrm{~m}$ are not included in the statistics.

(equal area) grid. Similar discrepancies due to a different method application or data preparation cannot be ruled out.

According to the method-specific intensity parameter (see Table 1), the 1500 strongest cyclones per method were selected from the $20 \mathrm{C}$ period and considered as intense cyclones. The respective individually defined intensity threshold is also used for the identification of strong cyclones under climate change forcing. Note that the methods identify different numbers of cyclones, and this 'intense' class represents between $4 \%$ and $9 \%$ of all cyclones, depending on the scheme. Fig. 1b shows the track density of the method mean of those intense cyclones. Restricting the evaluation to these intense systems, it turns out that the distribution between methods is rather similar, even though differences are apparent (supplemental material ${ }^{2}$ ). One reason for such differences in the pattern of extreme cyclones seems related to track lengths, arising from the method-dependent assignment of cyclone positions at different time steps to a track.

The climate change signals are estimated simply by taking the difference of cyclone track densities between the A1B (2061-2100) and 20C (1961-2000) forcing periods (method mean and agreement between methods shown in Fig. 3a). Signals based on each individual method are mostly significant according to a local t-test at the $95 \%$ level taking the interannual variability at each grid point into account. The change patterns are largely similar between methods. In particular, there are many common areas with decreasing track densities. For the Mediterranean region $\left(30^{\circ} \mathrm{N}-45^{\circ} \mathrm{N} / 0^{\circ} \mathrm{E}-40^{\circ} \mathrm{E}\right.$; red

\footnotetext{
${ }^{2}$ Supplemental information related to this paper is available on the journals website at www.schweizerbart.de/journals/metz.
}

box in Fig. 3a) the mean track density signal spreads between $-16 \%$ and $-38 \%$, except one method which shows an increase of about 6\% (Fig. 4a). Additional decrease can be identified in the Barents and Greenland Seas, the mid-latitude Pacific and North America with $10 \%$ to $-20 \%$ for e.g. the Arctic between $0^{\circ}$ and $30^{\circ} \mathrm{E}$ (supplemental material). Increases in cyclone track densities are consistently found over parts of Asia, in the Bering Sea, and in the eastern North Atlantic west of the British Isles. The latter region $\left(48^{\circ} \mathrm{N}-62^{\circ} \mathrm{N} / 40^{\circ} \mathrm{W}\right.$ $0^{\circ} \mathrm{W}$; blue box in Fig. 3) shows changes between $-3 \%$ and $9 \%$, whereas only one method shows a decrease of cyclones (Fig. 4b). The change in this region is highly influenced by strong cyclones which are consistently tracked by the different methods. For strong cyclones, the changes in the North Atlantic box range from about $20 \%$ to $35 \%$ (not shown). For all cyclones, the huge spread in this box can be assigned to a different manifestation of the strength distribution due to a different handling of shallow cyclones. There are also small areas where the different methods disagree, for example in an area west of Greenland (Baffin Bay/Davis Strait), which exhibits increasing cyclone track frequencies in M02, M15 and M20, but decreasing values in M09, M12, M16 and M22.

It is insightful to compare the change patterns of each method with the method-ensemble mean signal using a Taylor diagram. The agreement of the patterns is high (Fig. 5) with correlations between 0.82 and 0.95 (except for M21, which has a lower correlation of $r=0.62)$ and broadly consistent levels of spatial variance. While there are clear indications of local changes, it is also interesting to consider zonal averages of the changes (Fig. 6). Differences between methods emerge more clearly under this approach (not shown). While there are decreasing cyclone track densities south of about $50^{\circ} \mathrm{N}$, and increasing ones close to the pole in all methods, changes at latitudes around $60^{\circ} \mathrm{N}$ are somewhat less clear, with small changes of different sign.

There is a clear signal of increasing numbers of intense cyclones over the NH (Fig. 3b), with maxima in the area of the Aleutian Islands and over the eastern North Atlantic, with a maximum north of Scotland in every single method (supplemental material ${ }^{2}$ ). These increases are statistically significant at the $95 \%$ level, and indeed are so over most of the Pacific and Arctic Oceans. In contrast to the nature of the changes for all cyclones, the signal for strong cyclones has the same order of magnitude for each method. Almost all investigated methods show no significant decrease with respect to these intense cyclones.

\section{Concluding remarks}

Eleven different methods for cyclone detection and tracking have been applied to a particular ECHAM5/OM1 model run under transient greenhouse gas forcing. In spite of differences in absolute cyclone track numbers 
(a)
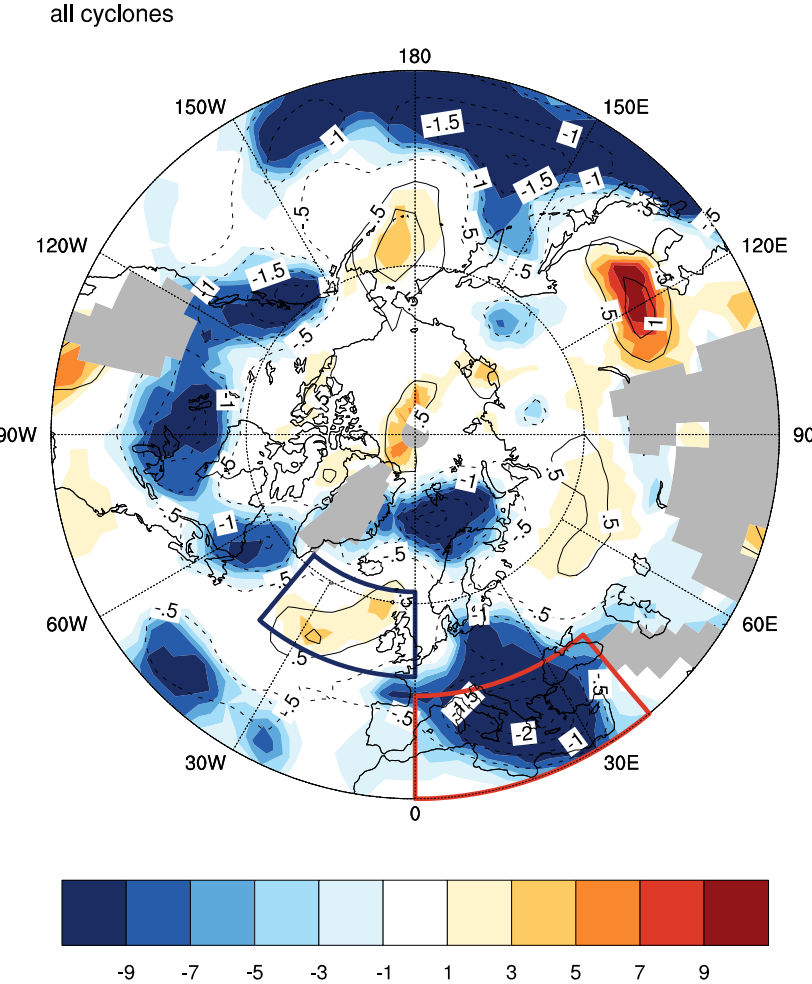

(b)
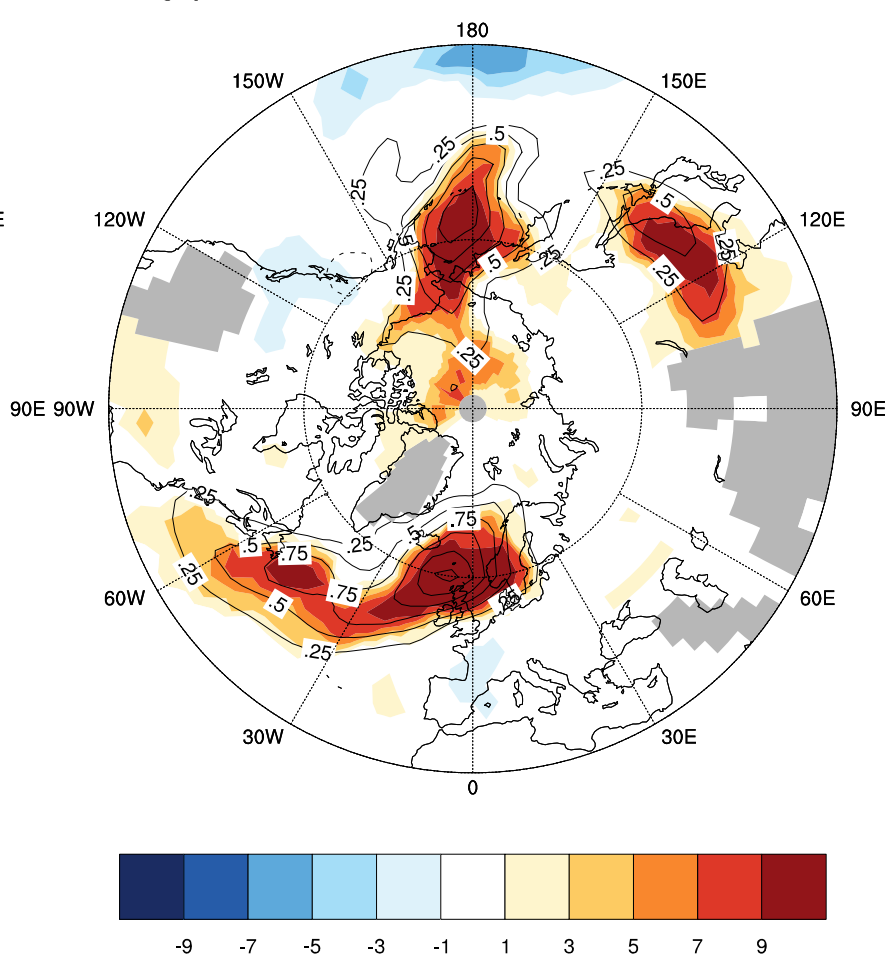

Figure 3: Number of methods showing a significant (0.95) climate signal of track density (shading) and absolute values of the method mean signal [tracks/winter lat ${ }^{-2}$ ] (isolines) for a) all and b) strong cyclones. Blue/red shadings indicate number of methods with significant negative/positive changes. Contour level of isolines is a) 0.5 [tracks/winter lat ${ }^{-2}$ ] and b) 0.25 [tracks/winter lat ${ }^{-2}$ ], whereas solid/dashed lines indicate positive/negative changes. Areas with orography higher than $1500 \mathrm{~m}$ are masked out with grey shading. The red (Mediterranean) and blue (North Atlantic) boxes in a) mark areas used for Fig. 4.
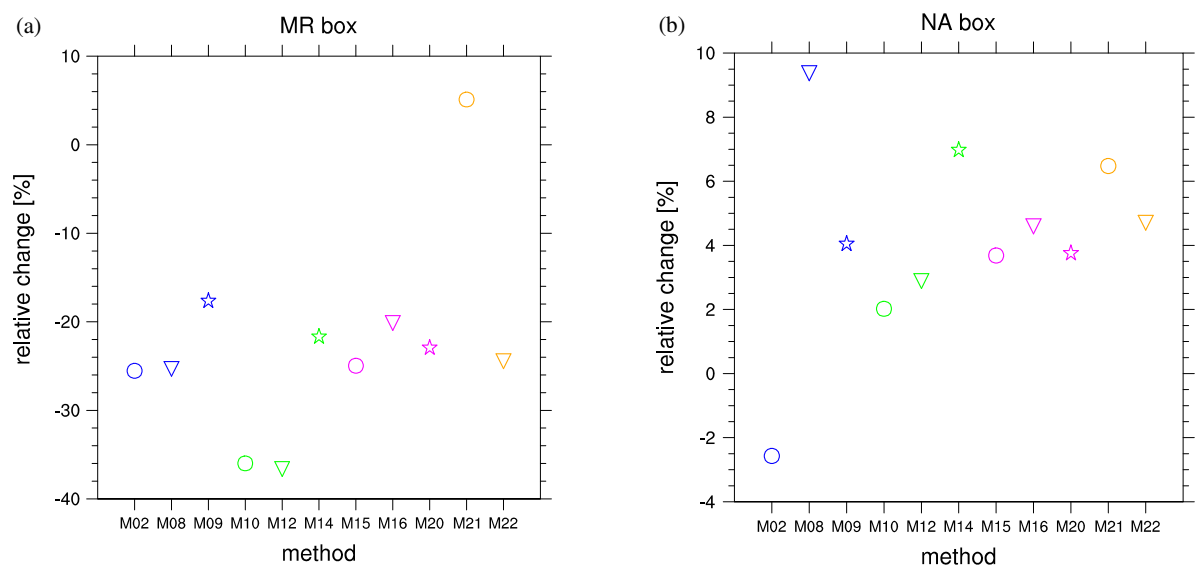

Figure 4: Relative (with respect to the $20 \mathrm{C}$ mean) change in cyclone track number - average in the a) Mediterranean Region (MR) $\left(30^{\circ} \mathrm{N}\right.$ $45^{\circ} \mathrm{N} / 0^{\circ} \mathrm{E}-40^{\circ} \mathrm{E}$; red box in Fig. 3a) and b) North Atlantic region (NA) $\left(48^{\circ} \mathrm{N}-62^{\circ} \mathrm{N} / 40^{\circ} \mathrm{W}-0^{\circ} \mathrm{W}\right.$; blue box in Fig. 3$)$.

between the different methods, the agreement between the results using these algorithms, both with respect to the distribution of cyclones and with respect to change signals, is an important result of our current work. There are further cyclone properties (e.g. cyclogenesis, cyclolysis) analysed by the algorithms (NEU et al., 2012), which are not investigated in the present study.
The patterns of model simulated present day climatologies are found to be close to those computed from reanalysis, independent of the method applied. Investigating the climate change signal, however, emphasises the differences between methods. The most noticeable differences are found for zonal mean values near $60^{\circ} \mathrm{N}$ (Fig. 6a). In this latitude belt most methods produce no 


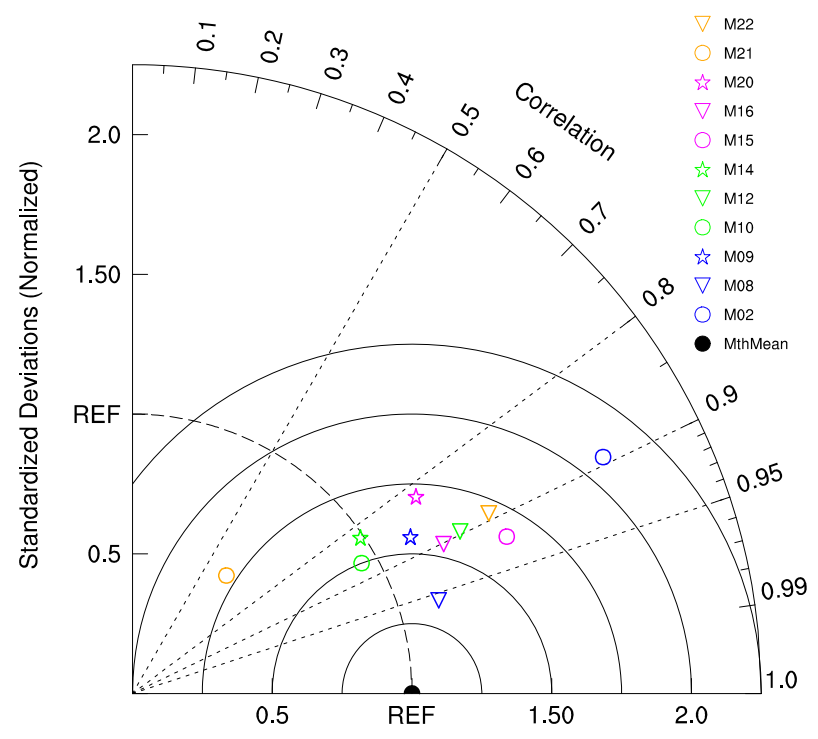

Figure 5: Taylor diagram of the climate-change-pattern similarity for the $\mathrm{NH}\left(20^{\circ} \mathrm{N}-90^{\circ} \mathrm{N}\right)$ between each method and the methodensemble mean (REF) for all cyclones. The $\mathrm{x}$ and $\mathrm{y}$ axis show the normalised standard deviation of the horizontal change pattern, whereas the pattern correlation is marked by the arc. Areas with orography higher than $1500 \mathrm{~m}$ are not included in the statistics.

statistically significant signal. For a small number of methods an increase can be identified, which is significant for one of them. It can be assigned to the strong cyclones, which increase consistently according to almost all methods (Fig. 6b). The fact that opposing signals are found in Fig. 6a can thus be assigned to the effect of weak cyclones and the maxima of their occurrence. This role differs between methods due to their characteristics in terms of the treatment of cyclones during phases of low intensity within their life cycle, for example.

With respect to the strongest cyclones, all methods are in agreement in producing an increasing number as climate change signal, with maxima over the Aleutians and over the eastern North Atlantic up to the British Isles. This result is in line with shorter return periods for extreme cyclones over this area (DELLA-MARTA and PINTO, 2009) and an increased storm risk in central Europe (e.g. SCHWIERZ et al., 2010; DONAT et al., 2011; PINTO et al., 2012), as wind storms are mainly located south of the cyclone cores in these areas. The analysed methods show a robust signal of decreasing tracks over the Mediterranean, where cyclones are generally weaker than over the North-Atlantic (NISSEN et al., 2010; KouROUTZOGLOU et al., 2011). Here, this signal is dominated by a decreasing number of rather weak systems, which is found from all methods used in the present study. The result for the single model run considered here also agrees with the (multi-model ensemble based) result of increasing variability of synoptic scale sea level pressures west of central Europe found by ULBRICH et al. (2008) for CMIP3 runs and by HARVEY et al. (2012) for CMIP5 runs. Recent studies document that cyclone activity in the multi-model CMIP5 runs has a similar (though weaker) signal compared to the results described here (MIZUTA, 2012).

Overall, the dominant regional signals of anthropogenic greenhouse gas forcing agree between all of the state-of-the-art methods examined here. We found that the differences between the methods considered are largely due to the different role of weaker systems in the specific methods. Their number is mostly reduced under increasing greenhouse gas forcing, in contrast to the signal for intense systems. While it is obvious that an agreement of changing signals cannot be expected for small areas, it is more surprising that zonal averaging (compared to a consideration of patterns) can emphasize differences in the algorithm. Again, we assign this fact to the differences in absolute numbers of detected cyclones, and thus to the question which weak entities should be counted as a cyclone. It should be noted that the overall agreement of signals is related to the fact that the meth-
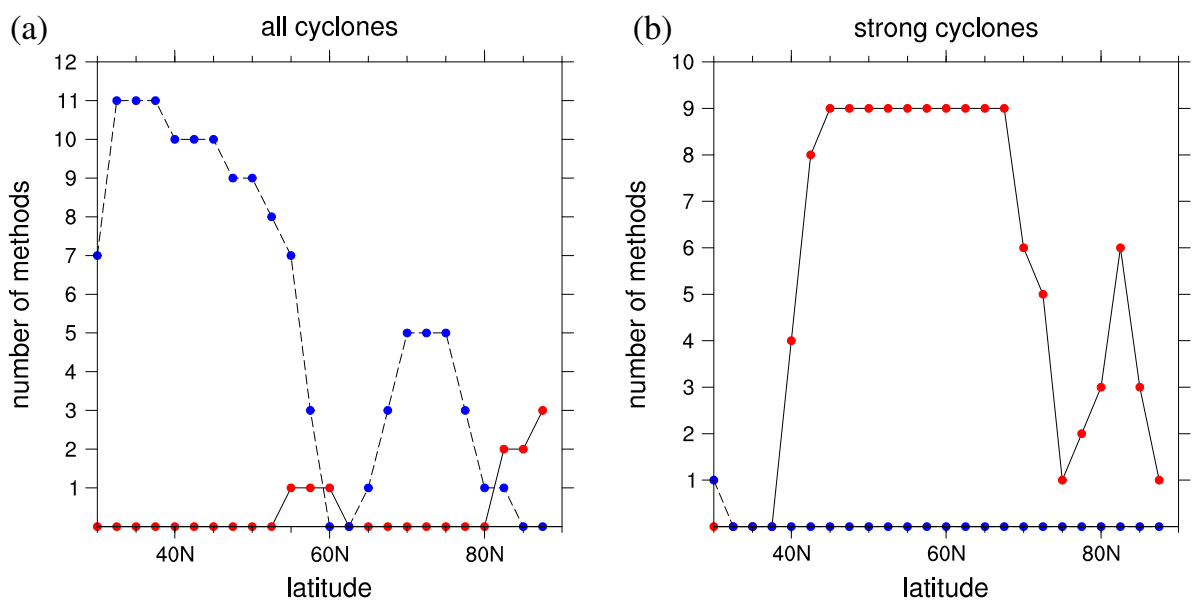

Figure 6: Number of methods showing a significant (0.95) increase (red and solid line) and decrease (blue and dashed line) of track density with respect to the NH zonal mean for a) all and b) strong cyclones. Areas with orography higher than $1500 \mathrm{~m}$ are not included in the statistics. 
odologies used in this paper have a common focus on cyclone cores. Methods looking at a measure like the 2-6 day bandpass filtered variance of sea level pressure may show a spatially shifted signal (compare signals with those using bandpass filtered variance as presented in ULBRICH et al., 2008). Still, the main message is that obviously even in this case the processes behind the signals agree with each other, and it is just the different parameters considered which lead to slightly different signals and characteristics. The message for the scientific community, however, is obvious: The different methodologies agree in terms of an increasing number of intense cyclones over the Aleutian region and the eastern North Atlantic, which support respective findings on windstorm risk, for example. While we have just considered one model run here, these results are in line with multi model studies using individual methods.

\section{Acknowledgments}

We thank Swiss Re for sponsoring the project IMILAST (coordination office and workshops) and ECWMF for providing the input data of ERA Interim. M.L.R. LIBERATO and I.F. TRIGO were supported by the FCT (Portugal) through project ENAC (PTDC/AAC-CLI/103567/ 2008). J. GRIEGER and M. SCHUSTER were supported by the DFG project SACAI (DFG-LE1865/1-3). M. AKPEROV and I. MOKHOV were supported by the Russian Ministry of Education and Science (8617).

\section{References}

AKPerov, M., M. Y. BARdin, E. M. Volodin, G. S. GOLITSYN, I. I. MOKHOV, 2007: Probability distributions for cyclones and anticyclones from the NCEP/NCAR reanalysis data and the INM RAS climate model-Izvestiya, Atmos. Oceanic Phys. 43, 705-712.

BArdin, M. Y., A. B. PolOnSKY, 2005: North Atlantic Oscillation and synoptic variability in the Europeanatlantic region in winter. - Izvestiya, Atmos. Ocean. Phys. 41, 127-136.

Bengtsson, L., K. I. Hodges, E. RoecKner, 2006: Storm tracks and climate change. - J. Climate. 19(15), 35183543.

BLENDER, R., K. FrAEDRICH, F. LunKEIT, 1997: Identification of cyclone-track regimes in the North Atlantic. Quart. J. Roy. Meteor. Soc. 123, 727-741.

DeE, D. P., S. M. UpPala, A. J. Simmons, P. BerRisford, P. Poli, S. Kobayashi, U. Andrae, M. A. Balmaseda, G. Balsamo, P. Bauer, P. Bechtold, A. C. M. BeljaArs, Van De L. Berg, J. Bidlot, N. BORMANN, C. Delsol, R. Dragani, M. Fuentes, A. J. Geer, L. Haimberger, S. B. Healy, H. Hersbach, E. V. Holm, L. ISAKSEN, P. KALLBERG, M. KOHLER, M. MATRICARDI, A. P. McNally, B. M. Monge-Sanz, J. J. Morcrette, B. K. Park, C. Peubey, De P. Rosnay, C. Tavolato, J. N. THEPAUT, F. VITART, 2011: The ERA-Interim reanal- ysis: configuration and performance of the data assimilation system. - Quart. J. Roy. Meteor. Soc. 137, 553-597.

Della-Marta, P. M., J. G. PINTO, 2009: Statistical uncertainty of changes in winter storms over the North Atlantic and Europe in an ensemble of transient climate simulations. - Geophys. Res. Lett. 36, L14703.

Donat, M. G., G. C. LeCKebUSCh, S. Wild, U. Ulbrich, 2011: Future changes in european winter storm losses and extreme wind speeds inferred from GCM and RCM multimodel simulations. - Natural Hazards Earth Sys. Sci. 11, 1351-1370.

HARVEY, B. J., L. C. Shaffrey, T. J. WoOllings, G. ZAPPA, K. I. HODGES, 2012: How large are projected 21st century storm track changes?. - Geophys. Res. Lett. 39, L18707.

Hoskins, B. J., P. J. VAldES, 1990: On the existence of storm-tracks. - J. Atmos. Sci. s. 47, 1854-1864.

INATSU, M., 2009: The Neighbor Enclosed Area Tracking algorithm for extratropical wintertime cyclones. - Atmos. Sci. Lett. 10, 267-272.

Kew, S. F., M. Sprenger, H. C. DAvies, 2010: Potential vorticity anomalies of the lowermost stratosphere: A 10-yr winter climatology. - Mon. Wea. Rev. 138, 1234-1249.

Kouroutzoglou, J., H. A. Flocas, I. Simmonds, K. KEAY, M. HATZAKI, 2011: Assessing characteristics of mediterranean explosive cyclones for different data resolution. - Theo. Appl. Climatol. 105, 263-275.

Leckebusch, G. C., M. G. Donat, U. Ulbrich, J. G. PINTO, 2008: Mid-latitude cyclones and storms in an ensemble of european AOGCMs under ACC. - CLIVAR Exchanges. 13, 3-5.

LiOnello, P., F. DAlAN, E. Elvini, 2002: Cyclones in the mediterranean region: the present and the doubled $\mathrm{CO}_{2}$ climate scenarios. - Climate Res. 22, 147-159.

LÖPTIEN, U., O. ZOLINA, S. GULEV, M. LATIF, V. SOlOVIOV, 2008: Cyclone life cycle characteristics over the northern hemisphere in coupled GCMs. - Climate Dynam. 31, 507532.

MizUTA, R., 2012: Intensification of extratropical cyclones associated with the polar jet change in the CMIP5 global warming projections. - Geophys.l Res. Lett. 39, L19707.

MurRAY, R., I. SIMMONDS, 1991a: A numerical scheme for tracking cyclone centres from digital data. part I: developement and operation of the scheme. - Australian Meteor. Magazine 39, 155-166.

MURRAY, R., I. SIMMONDS, 1991b: A numerical scheme for tracking cyclone centres from digital data. part II: Application to january and july general circulation model simulations. - Australian Meteor. Magazine 39, 167-180.

NeU, U., M. G. AKperov, N. Bellenbaum, R. Benestad, R. Blender, R. CABAllero, A. Cocozza, H. F. DACre, Y. Feng, K. Fraedrich, J. Grieger, S. Gulev, J. HANLEy, T. Hewson, M. InATSU, K. KeAY, S. F. KEW, I. Kindem, G. C. Leckebusch, M. L. R. Liberato, P. Lionello, I. I. MoKhov, J. G. Pinto, C. C. Raible, M. ReAle, I. RudeVA, M. Schuster, I. Simmonds, M. Sinclair, M. Sprenger, N. D. Tilinina, I. F. Trigo, S. Ulbrich, U. Ulbrich, X. L. WANG, H. WernLI, 2012: 
IMILAST - a community effort to intercompare extratropical cyclone detection and tracking algorithms. - Bull. Amer. Meteor. Soc. DOI:10.1175/BAMS-D-11-00154.1.

Nissen, K. M., G. C. Leckebusch, J. G. Pinto, D. RENGGLI, S. Ulbrich, U. Ulbrich, 2010: Cyclones causing wind storms in the mediterranean: Characteristics, trends and links to large-scale patterns. - Natural Hazards Earth Sys. Sci. 10, 1379-1391.

Pinto, J. G., T. Spangehl, U. Ulbrich, P. SPETh, 2005: Sensitivities of a cyclone detection and tracking algorithm: Individual tracks and climatology. - Meteorol. Z. 14, 823-838.

Pinto, J. G. , U. Ulbrich, G. C. LeCKebusCh, T. SPANGEHL, M. REYERS, S. ZACHARIAS, 2007: Changes in storm track and cyclone activity in three SRES ensemble experiments with the ECHAM5/MPI-OM1 GCM. - Climate Dynam. 29, 195-210.

Pinto, J. G. , M. K. Karremann, K. Born, P. M. DellaMARTA, M. KLAWA, 2012: Loss potentials associated with european windstorms under future climate conditions. Climate Res. 54, 1-20.

Raible, C. C., P. M. Della-Marta, C. Schwierz, H. WERNLI, R. BLENDER, 2008: Northern hemisphere extratropical cyclones: A comparison of detection and tracking methods and different reanalyses. - Mon. Wea. Rev. 136, 880-897.

ROECKNER, E., G. BÄUML, L. BONAVENTURA, R. BROKOPF, M. Esch, M. Giorgetta, S. HAGEMANN, I. Kirchner, L. KornblueH, E. MANZINI, A. RhOdIN, U. Schlese, U. SCHULZWEIDA, A. TOMPKINS, 2003: The atmospheric general circulation model ECHAM 5. part I: Model description.Max Planck Institute for Meteorology Report 349.

RudeVA, I., S. K. GuLEV, 2007: Climatology of cyclone size characteristics and their changes during the cyclone life cycle. - Mon. Wea. Rev. 135, 2568-2587.

SCHNEIDEREIT, A., R. BLENDER, K. FRAEDRICH, 2010: A radius-depth model for midlatitude cyclones in reanalysis data and simulations. - Quart. J. Roy. Meteor. Soc. 136, 50-60.

Schwierz, C., P. Kollner-Heck, E. Z. Mutter, D. N. Bresch, P. L. VidAle, M. WiLD, C. SCHAR, 2010:
Modelling european winter wind storm losses in current and future climate. - Climatic Change 101, 485-514.

SERrezE, M. C., 1995: Climatological aspects of cyclone development and decay in the arctic. - Atmosphere-Ocean. 33, 1-23.

SiEnZ, F., A. SCHNEIDEREIT, R. BLENDER, K. FrAEDRICH, F. LUNKEIT, 2010: Extreme value statistics for North Atlantic cyclones. - Tellus Series A-dynamic Meteorology and Oceanography 62(4), 347-360.

SimmondS, I., C. BURKE, K. KEAY, 2008: Arctic climate change as manifest in cyclone behavior. - J. climate. 21, 5777-5796.

TRIGO, I., 2006: Climatology and interannual variability of storm-tracks in the Euro-Atlantic sector: A comparison between ERA-40 and NCEP/NCAR reanalyses. - Climate Dynam. 26, 127-143.

Ulbrich, U., J. G. Pinto, H. Kupfer, G. C. Leckebusch, T. SPANGEHL, M. REYERS, 2008: Changing Northern Hemisphere storm tracks in an ensemble of IPCC climate change simulations. - J. climate. 21, 1669-1679.

Ulbrich, U., G. C. LeCKebusCh, J. G. PINTO, 2009: Extratropical cyclones in the present and future climate: A review. - Theo. Appl. Climatol. 96, 117-131.

WANG, X., Y. FenG, G. COMPO, V. SwaIl, F. ZWIERS, R. Allan, P. SARDESHMUKh, 2012: Trends and low frequency variability of extra-tropical cyclone activity in the ensemble of twentieth century reanalysis. - Climate Dynam., published online, DOI:10.1007/s00382-0121450-9.

WANG, X. L. L., V. R. SWAIL, F. W. ZWIERS, 2006: Climatology and changes of extratropical cyclone activity: Comparison of ERA-40 with NCEP-NCAR reanalysis for 1958-2001. - J. Climate 19, 3145-3166.

WERNLI, H., C. SCHWIERZ, 2006: Surface cyclones in the ERA-40 data set (1958-2001). part I: Novel identification method and global climatology. - J. Atmos. Sci. 63, 24862507.

ZOLINA, O., S. K. GULEV, 2002: Improving accuracy of mapping cyclone numbers and frequencies. - Mon. Wea. Rev. 130, 748-759. 

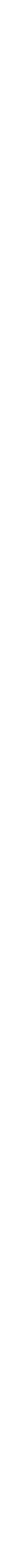

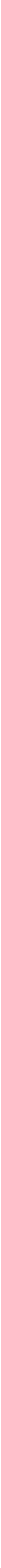
